\title{
Optimization Study on Expansion Energy Used Air-Powered Vehicle with Pneumatic-Hydraulic Transmission
}

\author{
Xiang-Heng Fu ${ }^{1,2}$, Mao-Lin Cai ${ }^{1,2}$, Yi-Xuan Wang ${ }^{1,2}$ and Yan Shi ${ }^{1,2^{*}}$
}

\begin{abstract}
Pneumatic-hydraulic transmission has been developed for years. However, its dynamic properties are not good enough for application. In this paper, in order to increase the output characteristics, a late-model air-powered vehicle using expansion energy is proposed which can boost energy through a pneumatic-hydraulic transmission. The dynamic characteristics of the air-powered vehicle is modeled and verified by conducting experiment. In addition, the influence of the key parameters of the air-powered vehicle is researched for the optimization of the system performance. Through the results, the author got the conclusion that, firstly, comparison of the results of model and experiment proves the built model to be effective; secondly, input air pressure should be set according to the request of the practical loads, and range of 0.65 to $0.75 \mathrm{MPa}$ can be chosen; thirdly, as a key structure parameter of the airpowered vehicle, ratio of the areas is considered to be set to approximate 8 ; what's more, a bigger orifice with a limit will promote the system dynamic characteristic property, and the limit is about $3.5 \mathrm{~mm}$; last but not the least, not too farther position of the rings will increase the quality of output dynamic characteristics. This paper can be a reference for system design of air-powered vehicle and dynamic improvement.
\end{abstract}

Keywords: Air-powered vehicle, Expansion energy, Pneumatic-hydraulic transmission, Output dynamic characteristics

\section{Introduction}

Recently, for advantages of anti-explosion, zero-emission, and pollution-free, sustainable energy vehicles suitable for friendly environments have been widely adopted as a late model green transport. Main part of sustainable energy vehicles is air-powered engine, and the pneumatic-hydraulic transmission is broadly applied as the main heart of the driving system for great advantages of simple structure, recyclability, low cost, high storage density of energy and long lifespan [1-3]. Though the advantages are obvious, it also owns disadvantages such as low efficiency by insufficient of the energy utilization, which aggravates the waste of energy, especially under

\footnotetext{
*Correspondence: yesoyou@gmail.com

1 School of Automation Science and Electrical Engineering, Beihang University, Beijing 100191, China

Full list of author information is available at the end of the article
}

the recent environment of energy shortage and developing green movements $[4,5]$.

The recent studies on the pneumatic and hydraulic transmission still mainly focus on method of optimizing the structure and performance [6]. Shen et al. [7] designed and implemented a type of air pump driven by input gas used in air-powered motorcycle, and its main process of the pressurizing is piston reciprocating motion. What is more, Takeuchi et al. [8] implemented the application of expansion energy of compressed air by designing a kind of expansion-type pump.

About the dynamic characteristics of the hydraulic model, a serial of works has been published in recent years. Many kinds of analysis about hydraulic and pneumatic model have been put forward. Ren et al. and Wang et al. studied the control method of a pneumatic servo system by using mathematic modelling and experimental research $[9,10]$. Yan et al. and Taleb et al. studied the
SpringerOpen

(c) The Author(s) 2018. This article is distributed under the terms of the Creative Commons Attribution 4.0 International License (http://creativecommons.org/licenses/by/4.0/), which permits unrestricted use, distribution, and reproduction in any medium, provided you give appropriate credit to the original author(s) and the source, provide a link to the Creative Commons license, and indicate if changes were made. 
pneumatic bi-cylinder transmission system without the pressurizing function by modelling and parameter analysis $[11,12]$. Cai et al. has improved the model based on a new-type of pneumatic-hydraulic transmission and analyzed the dynamic characteristics [13]. However, the traditional pneumatic-hydraulic transmission is energy dissipation because the air expansion energy existing in the compressed air is wasted. From then on, very little study on any type of sustainable vehicle driven by pneumatic-hydraulic transmission has been reported [14, 15], especially that using air expansion energy.

For promoting working efficiency by using the expansion energy of the compressed air, we proposed a new type of expansion energy used air-powered vehicle using pneumatic-hydraulic transmission. However, the application of air expansion energy used vehicle is still hard to achieve due to the lack of research on output dynamic characteristics, which caused trouble for the performance improvement of air-powered vehicles [16].

In this article, an air-powered vehicle using expansion energy of compressed air has been proposed. In order to set a foundation on the dynamic performance optimization of the air-powered vehicle, firstly, a late model airpowered vehicle with pneumatic-hydraulic transmission was modeled and experimentally verified. Secondly, output dynamic characteristics of the new kind of air-powered vehicle, including the output torque and revolving speed, were studied through simulation. What's more, output dynamic characteristics were studied by analyzing affection of several key structure parameters for inspecting the best performance of the air-powered vehicle with pneumatic-hydraulic transmission.

\section{Mathematical Modeling of the Air-Powered Vehicle}

Structure of the built air-powered vehicle with pneumatic-hydraulic transmission is shown in Figure 1. As we can see, the main part of the expansion energy used airpowered vehicle contains the pneumatic-hydraulic transmission and the Motor part, including one pneumatic cylinder and two symmetric hydraulic cylinders. The magnetic switching valve controls the input way of the air source. The pneumatic piston is directly driven by the input air. Through transmission of air pressure, hydraulic pistons move towards the same direction of pneumatic piston, then the hydraulic oil drives the hydraulic motor to work.

In the air-powered vehicle, the structure of magnetic rings of piston and magnetic inductors ensures the continuously working of the motor, what is more, the advantage of expansion energy of compressed air. As shown from Figure 2, the whole processes of one of the hydraulic pistons mainly contain four processes. At first, when

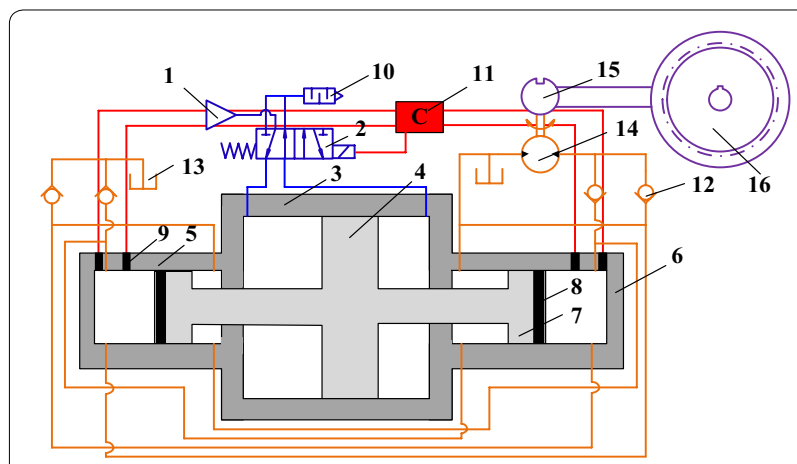

Figure 1 Configuration of the exoskeleton arm system. 1. Air source; 2. Magnetic switching valve; 3 . Pneumatic cylinder; 4 . Pneumatic piston; 5. Left hydraulic cylinder; 6. Right hydraulic cylinder; 7. Cylinder piston; 8. Magnetic ring of piston; 9. Magnetic inductor; 10. Muffler; 11. Controller; 12. Check valve; 13. Oil tank; 14. Hydraulic motor; 15. Drive link; 16. Motor of vehicle

the air was put into the pneumatic chamber, the hydraulic piston moves forward considered the first process. When the piston gets to the place of magnetic inductor $\mathrm{A}$, the source of air is stopped inputting by the controller, which can be considered as the second process. At this process, the vehicle is completely driven by the expansion energy of the compressed air in the pneumatic chamber. When the piston gets to the place of magnetic inductor $\mathrm{B}$, it works in reverse due to the change of the magnetic switching valve. The third and fourth processes are the same as the symmetrical hydraulic piston works in the same way. The time of third and fourth working processes of the pistons are completely using expansion energy, and the energy can be saved to some extent.

In the air-powered vehicle, the structure of magnetic rings of piston and magnetic inductors ensures the continuously working of the motor, what is more, the advantage of expansion energy of compressed air. As shown from Figure 2, the whole processes of one of the hydraulic pistons mainly contain four processes. At first, when the air was put into the pneumatic chamber, the hydraulic piston moves forward considered the first process. When the piston gets to the place of magnetic inductor, the source of air is stopped inputting by the controller, which can be considered as the second process. At this process, the vehicle is completely driven by the expansion energy of the compressed air in the pneumatic chamber. When the piston gets to the place of magnetic inductor $B$, it works in reverse due to the change of the magnetic switching valve. The third and fourth processes are the same as the symmetrical hydraulic piston works in the same way. The time of first and third working processes of the pistons are completely using expansion energy, and the energy can be saved to some extent. 


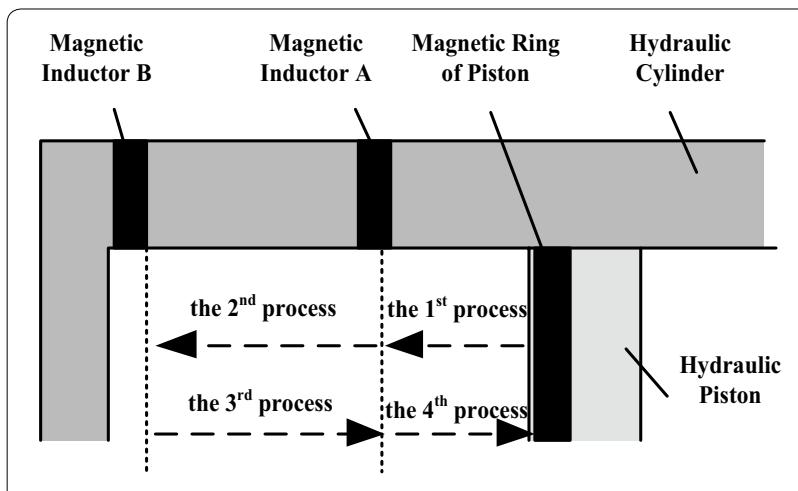

Figure 2 Working process of one hydraulic piston

According to the working principle of the expansion energy used air-powered vehicle, the mathematical model can be obtained as follows.

\subsection{Gas Energy Equations}

We consider the pneumatic chambers do not charge and exhaust air at the same time by assuming no leakage exists in pneumatic chambers. Consequently, gas energy equations for the inflating and deflating side of each chamber can be gotten as shown as follows $[17,18]$ :

$$
C_{\nu} W_{a} \frac{\mathrm{d} T}{\mathrm{~d} t}=\left(S_{t} \cdot h_{c}+C_{v} \cdot q\right)\left(T_{a}-T\right)+R_{0} q T_{a}-p A u,
$$

$$
C_{v} W_{a} \frac{\mathrm{d} T}{\mathrm{~d} t}=S_{t} \cdot h_{d}\left(T_{a}-T\right)+R_{0} q T-p A u,
$$

where $C_{v}$ is the specific heat at constant volume of the air; $W_{a}$ is the air mess; $S_{t}$ is the heat transfer area; $A_{p}$ is the area of the pneumatic piston; $u$ is the velocity of the pistons; $T$ is the temperature of the air; $T_{a}$ is the atmospheric temperature; $t$ is the real time; $R_{0}$ is the gas constant factor, which is usually $287 \mathrm{~J} /(\mathrm{kg} \cdot \mathrm{K})$.

\subsection{Ideal Pneumatic Continuity Equation}

According to the ratio of $P_{l} / P_{h}$, the pneumatic continuity equation for the flow through a restriction can be obtained as follows $[19,20]$ :

$$
q= \begin{cases}\frac{A_{e p} p_{h}}{\sqrt{T_{h}}} \sqrt{\frac{2 \kappa}{R_{0}(\kappa-1)}}\left[\left(\frac{p_{l}}{p_{h}}\right)^{\frac{2}{\kappa}}-\left(\frac{p_{l}}{p_{h}}\right)^{\frac{\kappa+1}{\kappa}}\right], & \frac{p_{l}}{p_{h}}>0.528, \\ \frac{A_{e p} p_{h}}{\sqrt{T_{h}}}\left(\frac{2}{\kappa+1}\right)^{\frac{1}{\kappa-1}} \sqrt{\frac{2 \kappa}{R_{0}(\kappa+1)}}, & \frac{p_{l}}{p_{h}} \leq 0.528\end{cases}
$$

where $A_{e p}$ is the effective area of the air ports; $p_{h}$ is the upstream side pressure; $p_{l}$ is the downstream side pressure; $\kappa$ is the specific heat ratio; $T_{h}$ is the upstream side temperature.

\subsection{Equation of State of Real Gas}

In each air chamber the pneumatic pressure changes can be written by differentiating equation of state of ideal gases:

$$
\frac{\mathrm{d} p}{\mathrm{~d} t}=\frac{1}{V}\left[\frac{p V}{\theta} \cdot \frac{\mathrm{d} \theta}{\mathrm{d} t}+R_{0} \theta q-p A u\right],
$$

where $p, V$ and $q$ stand for pressure, volume and mass flow of idea air, respectively.

\subsection{Motion Equation of the Pistons}

Piston velocity can be calculated by using Newton's second law of motion. What is more, the friction force model is considered as the sum of coulomb friction and viscous friction in this paper. All the forces on the piston can be shown from Figure 3.

Motion equation of the pistons can be written [21]:

$$
\begin{aligned}
& \frac{\mathrm{d}^{2} x}{\mathrm{~d} t^{2}}=\frac{1}{M}\left(p_{d l} \cdot A_{d l}-p_{d r} \cdot A_{d r}+p_{h A l} \cdot A_{h A l}\right. \\
& \left.-p_{h B l} \cdot A_{h B l}+p_{h A r} \cdot A_{h A r}-p_{h B r} \cdot A_{h B r}-F_{f}\right) \text {, } \\
& \frac{\mathrm{d} x}{\mathrm{~d} t}=0, \quad x=0, L, \\
& F_{f}= \begin{cases}F_{s}, & u=0, \\
F_{c}+C u, & u \neq 0,\end{cases}
\end{aligned}
$$

where $M$ is the mass of the piston; $x$ is the displacement of the piston; $A_{d l}$ is the equivalent areas of pneumatic piston in the left chamber; $A_{d r}$ is the equivalent areas of pneumatic piston in the right chamber; $A_{h A l}$ is the equivalent areas of hydraulic piston $\mathrm{A}$ in the left chamber; $A_{h A r}$ is the equivalent areas of hydraulic piston $\mathrm{A}$ in the right chamber; $A_{h B l}$ is the equivalent areas of hydraulic piston $\mathrm{B}$ in the left chamber; $A_{h B r}$ is the equivalent areas of hydraulic piston $\mathrm{B}$ in the right chamber; $P_{d l}$ is the air pressure in the left pneumatic chamber; $P_{d r}$ is the air pressure in the right pneumatic chamber; $P_{h A l}$ is the oil pressure of hydraulic cylinder A in the left chamber; $P_{h A r}$ is the oil pressure of hydraulic cylinder A in the right chamber; $P_{h B l}$ is the oil pressure of hydraulic cylinder $\mathrm{B}$

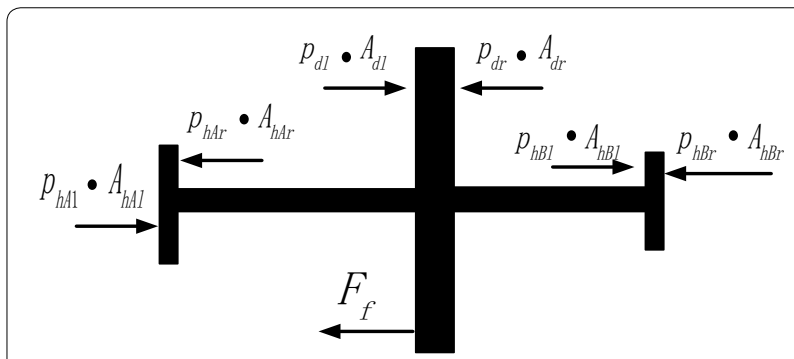

Figure 3 Forces on the pistons 
in the left chamber; $P_{h B r}$ is the oil pressure of hydraulic cylinder $\mathrm{B}$ in the right chamber.

What is more, $F_{f}$ is the force of the friction; $F_{c}$ and $F_{s}$ are force of coulomb friction and maximum static force of friction, respectively; $L$ stands for the piston stroke, and $C$ is the viscous friction factor.

\subsection{Hydraulic Pressure Equation}

The continuous equations of the hydraulic in the left and right chambers can be written as [22]:

$$
\begin{aligned}
& \frac{\mathrm{d} p_{d l}}{\mathrm{~d} t}=\frac{\beta}{V}\left(Q_{A i n}-Q_{A o u t}-A_{h A l} u\right), \\
& \frac{\mathrm{d} p_{d r}}{\mathrm{~d} t}=\frac{\beta}{V}\left(Q_{\text {Bin }}-Q_{\text {Bout }}+A_{h A r} u\right),
\end{aligned}
$$

where $Q_{A i n}$ is the input flow in hydraulic chamber A; $Q_{\text {Aout }}$ is the output flow in hydraulic chamber $\mathrm{A} ; Q_{B i n}$ is the input flow in hydraulic chamber $\mathrm{B} ; Q_{B o u t}$ is the output flow in hydraulic chamber $\mathrm{B} ; \beta$ is the effective bulk modulus.

\subsection{Flow Equation}

Volume flow of hydraulic oil through check valve can be written as follows [23]:

$$
Q=C_{d} A_{e h} \sqrt{\frac{2\left(p_{h}-p_{l}\right)}{\rho}},
$$

where $C_{d}$ is the flow factor of orifice of check valve, and $\rho$ is the density of hydraulic oil.

\subsection{Hydraulic Motor Equations}

As shown from Figure 1, upstream of the hydraulic motor is directly connected to the output of hydraulic chambers, and the downstream to oil tank, which the hydraulic pressure is nearly equal to atmospheric pressure. The basic equations of the working hydraulic motor can be written as Eqs. (10) and (11), includes hydraulic continuity equation and the moment equilibrium equation described as follows:

$$
\begin{gathered}
q_{\text {motor }}=C_{i m}\left(p_{1}-p_{2}\right)+C_{e m} p_{1}+D_{m} \frac{\mathrm{d} \theta_{m}}{\mathrm{~d} t}+\frac{V_{0}}{\beta} \cdot \frac{\mathrm{d} p_{1}}{\mathrm{~d} t}, \\
D_{m}\left(p_{1}-p_{2}\right)=J_{m} \frac{\mathrm{d}^{2} \theta_{m}}{\mathrm{~d} t^{2}}+B_{m} \frac{\mathrm{d} \theta_{m}}{\mathrm{~d} t}+G \theta_{m}+T_{L},
\end{gathered}
$$

where $q_{\text {motor }}$ is the hydraulic motor flow; $C_{i m}, C_{e m}$ are factors of internal and external leakage; $p_{w} p_{d}$ are motor upstream and downstream pressures; $J_{m}$ is the inertia factor; $B_{m}$ is the viscous damping factor; $G$ is the spring stiffness factor; $\theta_{m}$ is the motor output rotate speed; $V_{0}$ is the whole volume of motor chamber; $T_{L}$ is the whole other external load.

\section{Experimental Verification of the Mathematical Model}

As is shown in Figures 4 and 5, an experimental station of expansion energy used air-powered vehicle was set up. On the main output road there is a pressure sensor which tests the output hydraulic pressure, which can also be the upstream pressure of the motor; downstream pressure of the motor is the atmospheric pressure as it directly connects to the oil tank.

On output road of the pneumatic-hydraulic transmission there still has a flow inductor which can measure the output flow. The relief valve can make sure that the safety of the system pressure. We considered that no hydraulic flow passes through the regulator which means that the flow sensor measures whole flow into the motor. However, an over-high hydraulic system pressure will make the hydraulic flow pass through the regulator more than the over-loaded motor, which will to some extent affect the final results of the tests. In addition, a revolving speed measuring encoder is mounted on the motor shaft for testing the motor rotating speed.

Considering the system safety and the common characteristics, in the experiment a little-power hydraulic motor

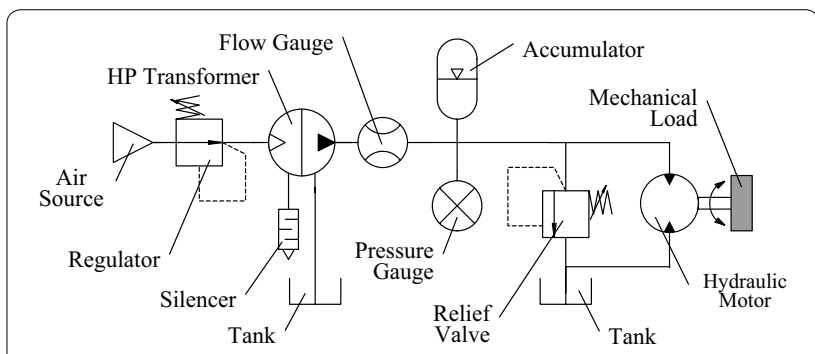

Figure 4 Sketch diagram of the air-powered vehicle

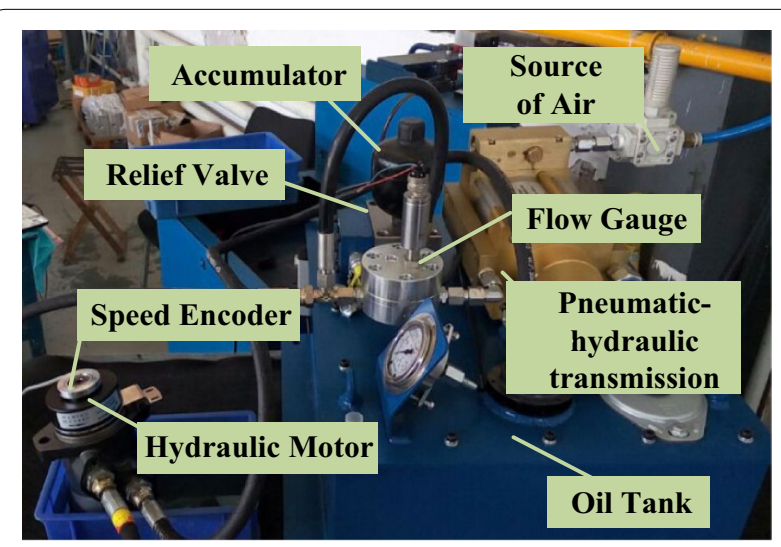

Figure 5 Experimental station of the air-powered vehicle 
with a relatively low-power load is chosen. The hydraulic regulator is set up to $2.0 \mathrm{MPa}$, and the pneumatic pressure of the input air is $0.67 \mathrm{MPa}$. Through several groups of experiments, the experimental curves were obtained after several collections of the signals. Results of flow and rotate speed of hydraulic motor from the experiments and simulations are shown in Figures 6 and 7, respectively.

As shown in Figure 6, the simulation and experimental results consist well with each other. Both curves from simulations and experiments are similar to pulse curves. However, the tops of the experimental curves are not quite stable comparing to the simulation ones. The reason for the instability is high stiffness of hydraulic system. There will be disturbance when the pistons of pneumatichydraulic transmission sharply shift. In addition, slight lag happens when the transmission shifts phase, and that is because in the hydraulic chambers the left hydraulic fluid left blocks the motion of the pistons.

As shown in Figure 7, motor rotate curves of simulation and experimental results match with each other, too. Amplifiers of the simulation curve is higher than that of

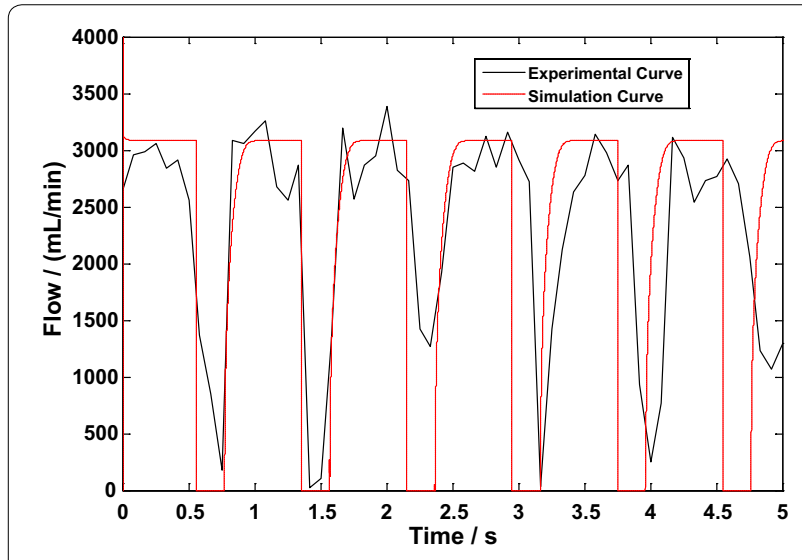

Figure 6 Simulation and experimental flow curves

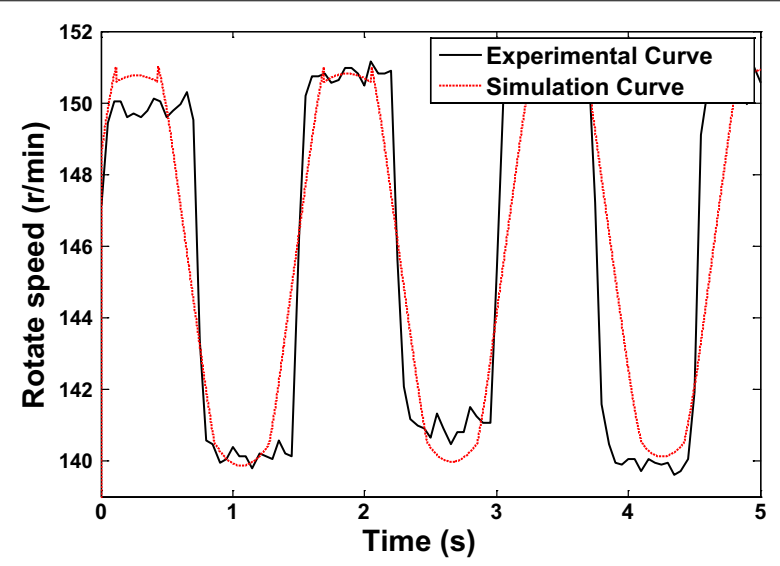

Figure 7 Simulation and experimental rotate speed curves the experimental one, that's because the regulator will open when the hydraulic pressure is over-high, and part of the flow separates from whole road through the motor, and that will limit the lifting of the motor rotator speed as the speed is related to the motor flow. What's more, the simulation result is much smoother than the experimental one. In the curve of the experimental result the sharps are caused by the limit of the encoder sensitivity.

\section{Dynamic Characteristics of Expansion Energy Used Air-Powered Vehicle}

Stability and comfort condition of output dynamic characteristics of hydraulic system greatly reflect the working performance and the service life. Researches on influencing factors of the air-powered vehicle were carried out for the optimization of sustainable energy vehicle. Recent studies conclude that parameters such as input air pressure $\left(p_{i n}\right)$, pistons area ratio $\left(A_{n}\right)$ and oil orifice $(R)$ in pneumatic and hydraulic cylinders will mostly influence the dynamic characteristics of pneumatic-hydraulic transmission. While for the expansion energy used pneumatic-hydraulic transmission compared with the original air-liquid transformer, structure of magnetic rings is the main difference and mostly reflects the characteristics.

Dynamic characteristics of rotate speed and output torque were studied, considering they can affect the working condition and lifetime of the air-powered vehicle. Rotate speed is determined by output flow which is mainly created by extrusion of piston directly during the moving time, and the flow through hydraulic motor establishes pressure based on the outside mechanical load which determines the output pressure of the hydraulic system and then reflects the output torque. We take the average rotate speed and torque values during each working process under difference working condition which can directly reflect the dynamic capability of the power system. What's more, variances of the output rotate speed and torque are calculated which can reflect the volatility of the dynamic characteristics and greatly affect the lifetime of the power system. In order to illustrate the influence, for the comparison, each parameter changes while other parameters keep constant. Then we get the final results as follows.

\subsection{Influence of Input Pressure on Dynamic Characteristics} As the energy source of power system, input pressure is usually used to reflect the output characteristics of pneumatic-hydraulic transmission. In the simulation, when areas ratio $(n)$ is set to 8 , oil orifice $(R)$ is set to $2.5 \mathrm{~mm}$ and input pressure $\left(p_{\text {in }}\right)$ is set to $0.55 \mathrm{MPa}, 0.65 \mathrm{MPa}$, and $0.75 \mathrm{MPa}$, the output dynamic characteristics of air-powered vehicle is analyzed.

As is shown from Figure 8, it's the torque curves of power system. All the curves start rising at first, decline 


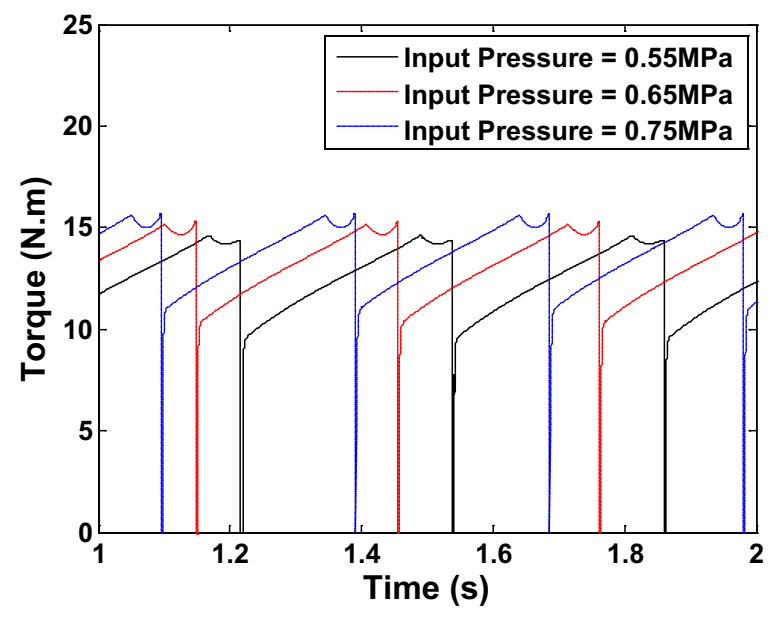

Figure 8 Torque-time curves

smoothly for a moment when reach the top valve, and fall down to the bottom sharply. That's because the torque is mainly directly obtained by output pressure which is directly determined by external load. At first, when output pressure is under the breakout pressure of hydraulic motor, the pressure keeps rising when the piston keeps moving and compressing the chamber space. This process won't last too long as the stiffness of hydraulic oil is high enough. When the piston gets the position of one of the magnetic ring, input air stops going into the pneumatic chamber, and the piston moves forward as the pressed air expands and the expansion energy will reduce, that's why the curves will smoothly decrease. As the piston gets the position of one of the switch rings, the piston changes the moving direction, and the pressure of the chamber will release as it is connected to the atmosphere. So the toquetime curves present statement as shown in Figure 8.

As is shown from Figure 9, curves of rotate speed are similar to those of the output torque. That's because rotate speed is related with the output flow of the motor which is immediately obtained by orifice throttle formula, and pressure between output chamber and inlet port of the motor directly makes up the output flow through the orifice of the chamber.

From Figures 10 and 11, in the system, higher the input air pressure is, higher the average torque and rotate speed are. Variances of torque and rotate speed won't apparently change. So the input air pressure should be set according to the request of the practical loads.

\subsection{Influence of Area Ratio on Dynamic Characteristics}

Directly piston area ratio determines the pressurizing level. In the simulation, when input pressure $\left(p_{i n}\right)$ is set to $0.65 \mathrm{MPa}$, oil orifice $(R)$ is set to $2.5 \mathrm{~mm}$ and areas ratio $(n)$ is set to 6,8 , and 10 , the output dynamic characteristics are studied as follows.

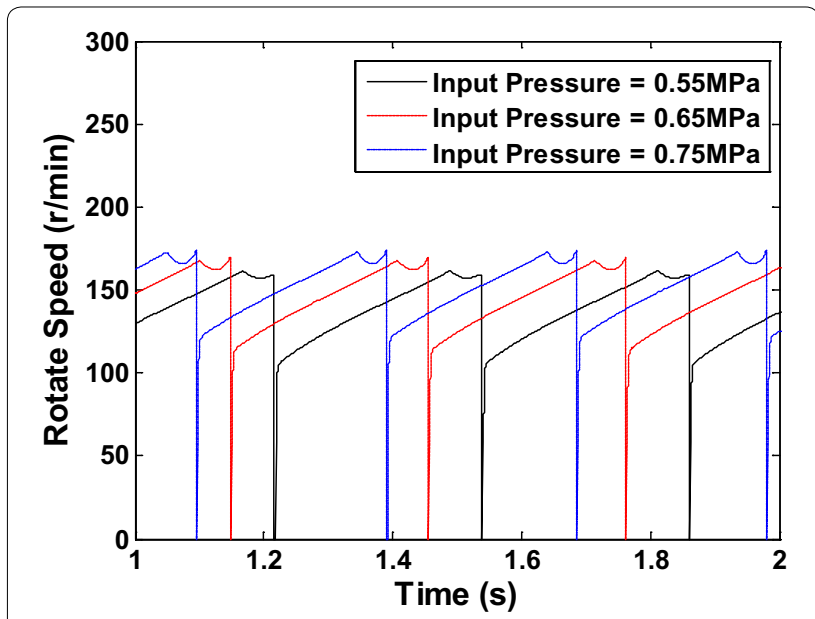

Figure 9 Rotate speed-time curves

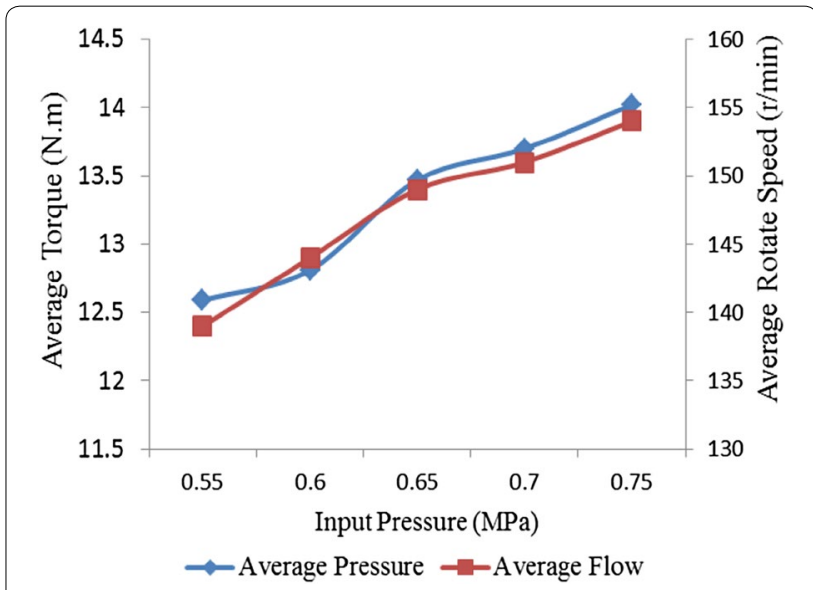

Figure 10 Average torque and rotate speed trend curves

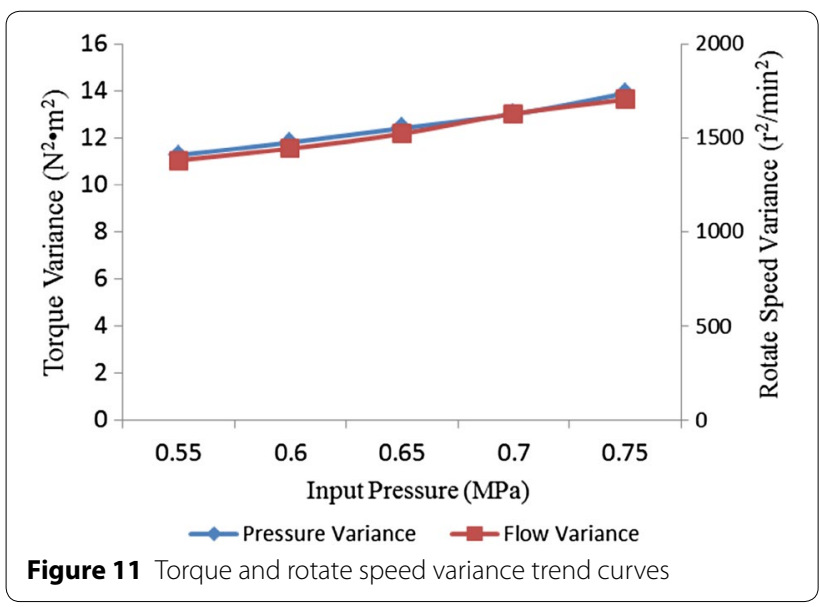

As shown of Figures 12 and 13, comparing with input air pressure, area ratio of power system will much more influence the output dynamic characteristics. From the figures, when area ratio is set to 6 , the output torque 


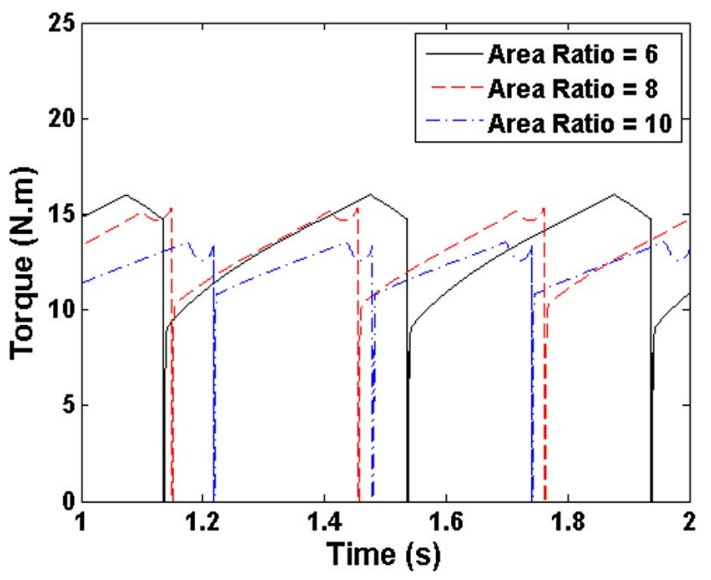

Figure 12 Torque-time curves

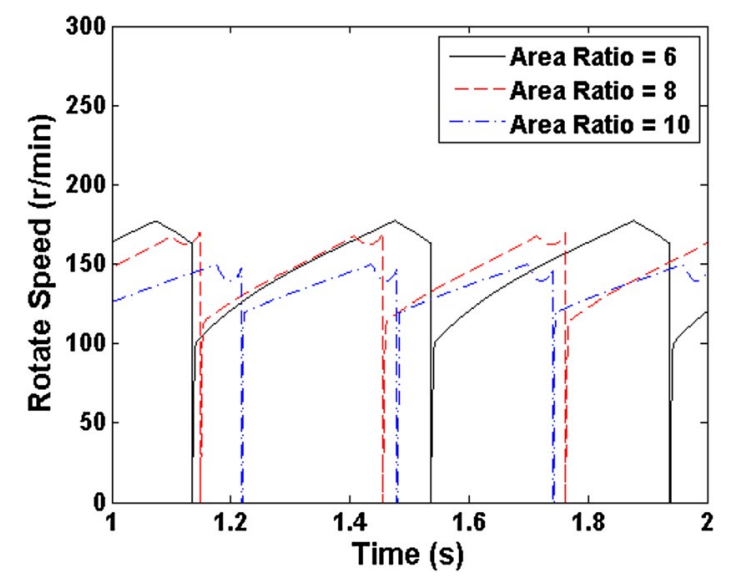

Figure 13 Rotate speed-time curves

and the rotate speed curves won't have sharp shocks and the curves are relatively smooth. As the area ratio is set larger, sharp points appear every working circle time.

From Figures 14 and 15, average torque and rotate speed curves increase at beginning of the circles and then reduce a lot. The highest point is at the time when the area ratio is set to 8 . Instead, torque and rotate speed variances reduce at first and increase then. Similarly, the lowest point is at the time when the area ratio is 8 . So area ratio of the power system is considered to be set to approximate 8 , which makes the system output capacity the highest and the dynamic characteristics the best.

\subsection{Influence of Orifice on Dynamic Characteristics}

In the simulation, when input pressure $\left(p_{i n}\right)$ is set to fixed $0.65 \mathrm{MPa}$ and areas ratio $(n)$ is set up to 8 , we set the oil orifice $(R)$ of the hydraulic chamber to $2.5 \mathrm{~mm}, 3.0 \mathrm{~mm}$ and $3.5 \mathrm{~mm}$, and the dynamic characteristics is analyzed.

Figures 16 and 17 show the condition of output dynamic characteristics influenced by orifice of the

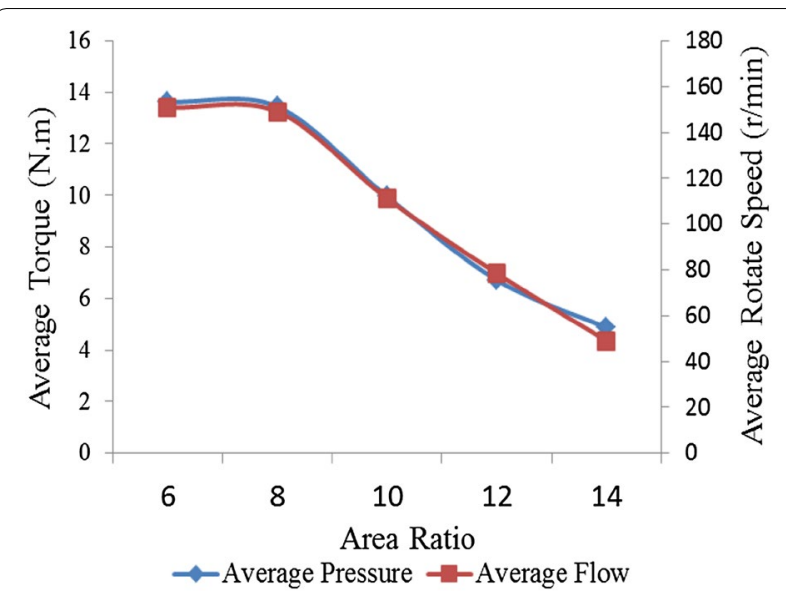

Figure 14 Average torque and rotate speed trend curves

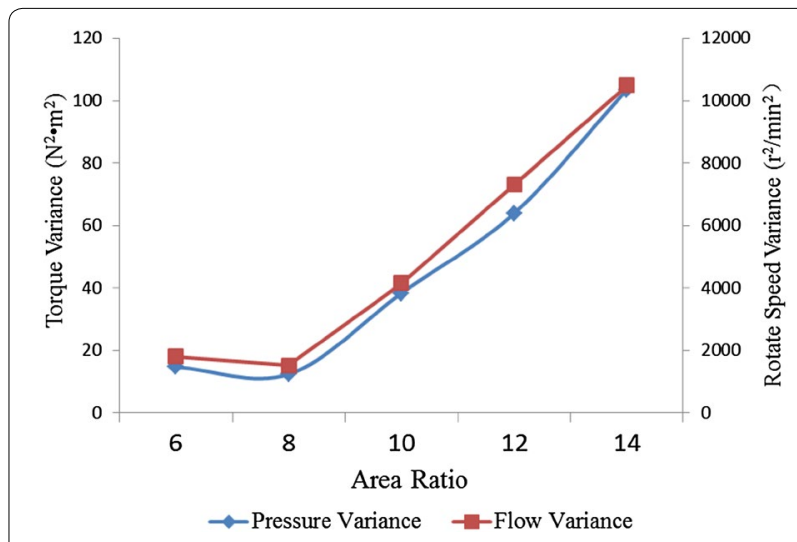

Figure 15 Torque and rotate speed variance trend curves

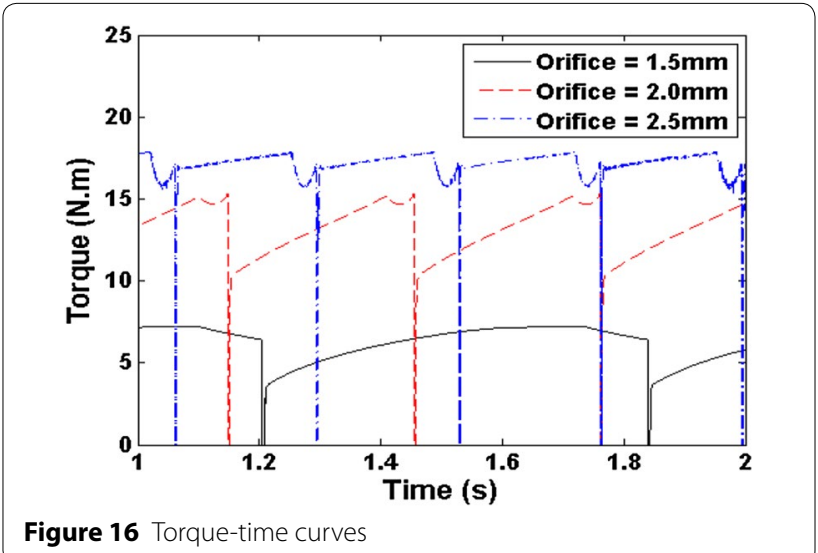

hydraulic chambers. It can be seen that valve of orifice effects the characteristics of the air-power system greatly. Based on the principle of oil through orifices throttling, the larger orifice is, the bigger output flow coefficient is. When the orifice is larger, the output flow will be 


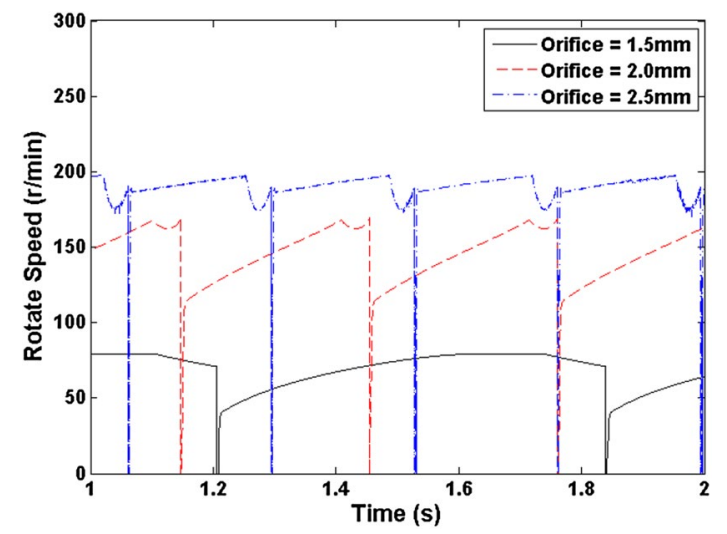

Figure 17 Rotate speed-time curves

promoted, and then it will obtain a higher rotate speed. The period of the rotate speed curves will be shorten when the output flow is relatively higher, too.

As we can see from Figures 18 and 19, a larger orifice will increase the output capacity of the system, including
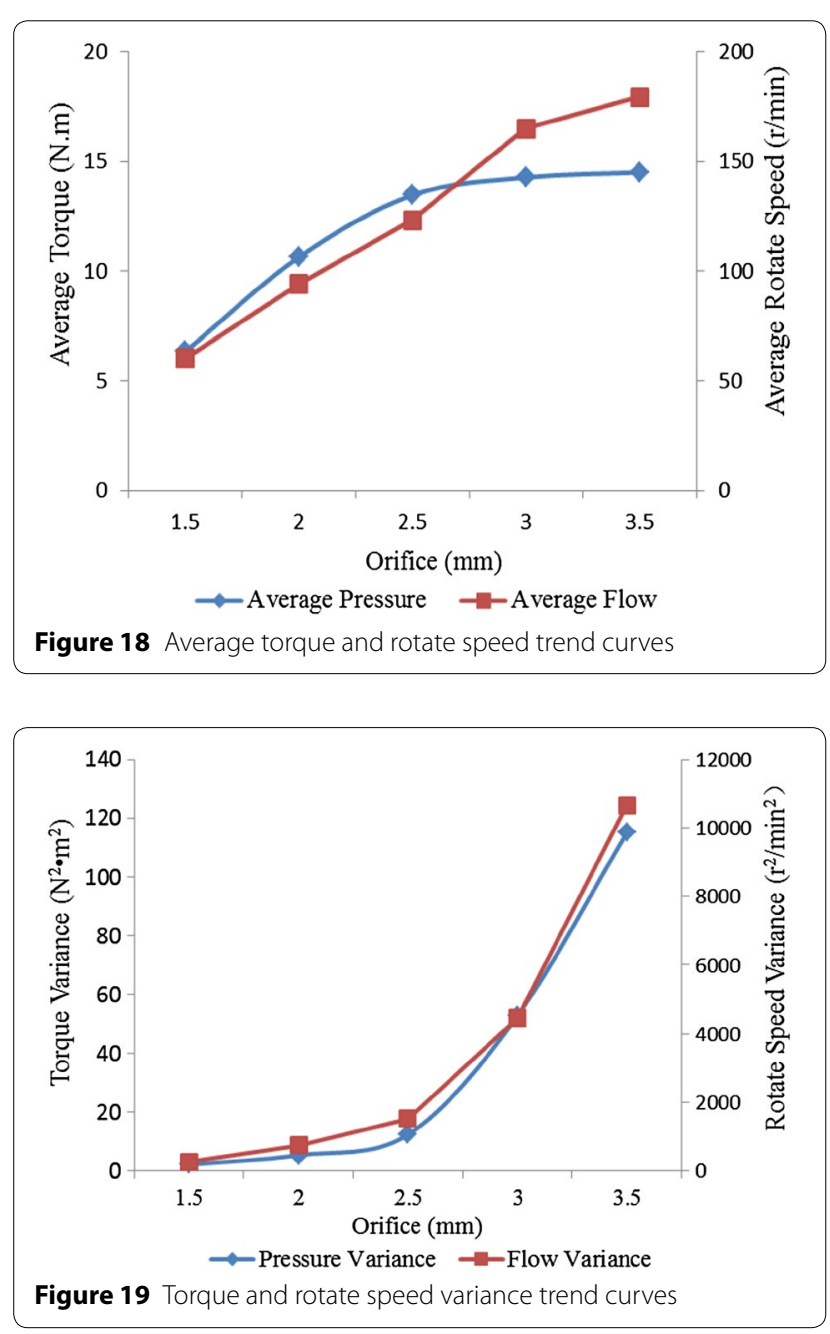

higher output torque and system rotate speed, which will allow the power system to drive a larger mechanical load. But when the orifice is too big, it will break the orifices throttling principle, which will disturb the pressure building of the system in the output chamber. As shown of all the figures above, under the condition of the experiment, the orifice is considered to be set about $2.5 \mathrm{~mm}$.

\subsection{Influence of Magnetic Ring on Dynamic Characteristics} Position of magnetic switch can be a key parameter of power system which can increase the system efficiency. When the piston stroke is set $1100 \mathrm{~mm}$, orifice of output hydraulic chamber $\left(R_{p}\right)$ is set to $2.5 \mathrm{~mm}$, input pressure of air source $\left(P_{i n}\right)$ to $0.65 \mathrm{MPa}$, and area ratio of pistons $\left(A_{p}\right)$ is set to 6, position of the magnetic switch $\left(L_{m}\right)$ is set to $0.015 \mathrm{~m}, 0.020 \mathrm{~m}$ and $0.025 \mathrm{~m}$, then we got the simulation results as follows.

The position of the magnetic ring is considered to be the key parameter of the structure of pneumatic-hydraulic transmission. As shown from Figures 20 and 21, when

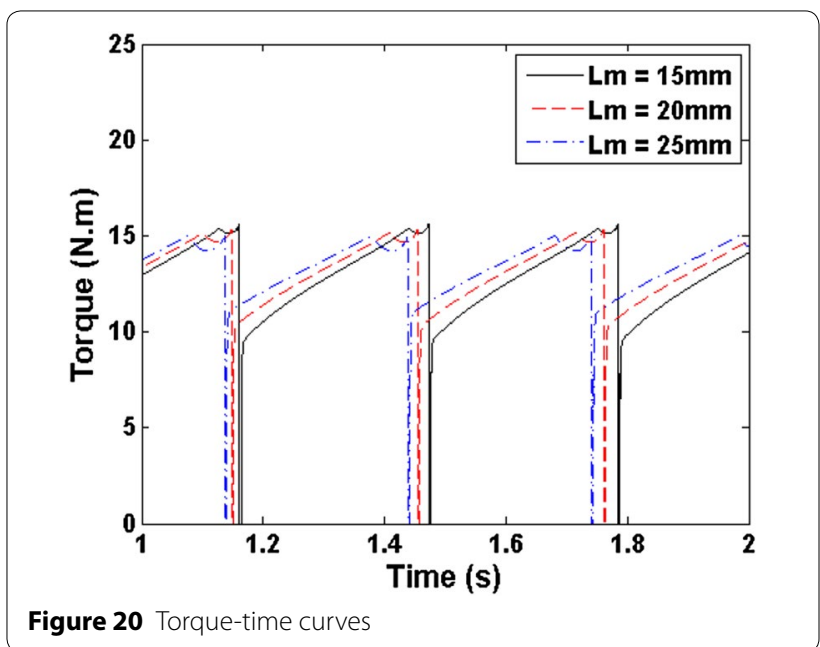

Figure 20 Torque-time curves

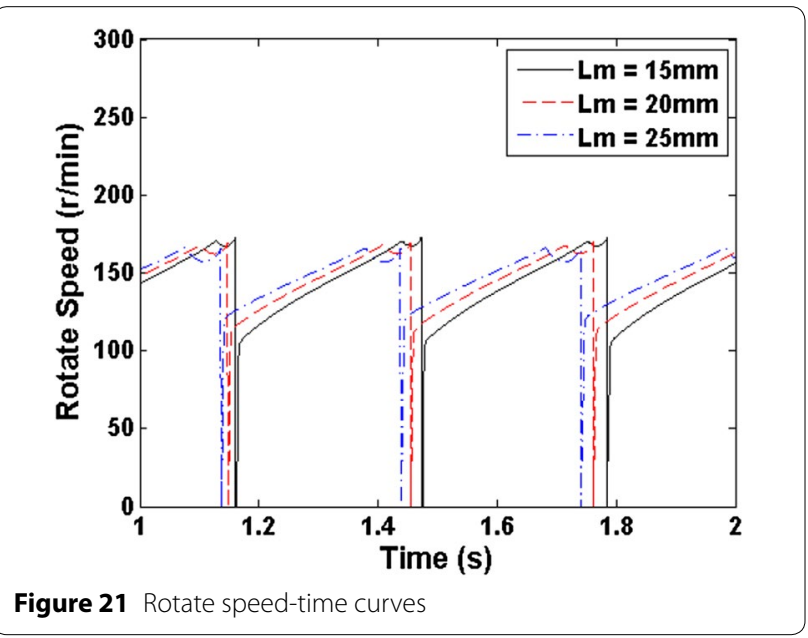


the position of the magnetic ring is set farther, the circle period of the curves will not be changed apparently, but they will be smoother from a whole view. That's because a farther position of the magnetic ring will not be obvious comparing with the whole piston stroke.

From Figure 22, farther position of the rings will promote the torque and the speed of the power system. When it is set lower than $20 \mathrm{~mm}$, it will increase sharply. When it is set above $20 \mathrm{~mm}$, the speed of the increase will become slow. Figure 23 shows that the farther the position is, the smaller the variances of torque and rotate speed will be. In addition, if the position is set too far, the piston will hardly get the magnetic switch, and the piston will stop moving. So for better output dynamic characteristics of the power system, the position setting of the magnetic ring can be about $20 \mathrm{~mm}$ when the piston stroke is $1100 \mathrm{~mm}$.

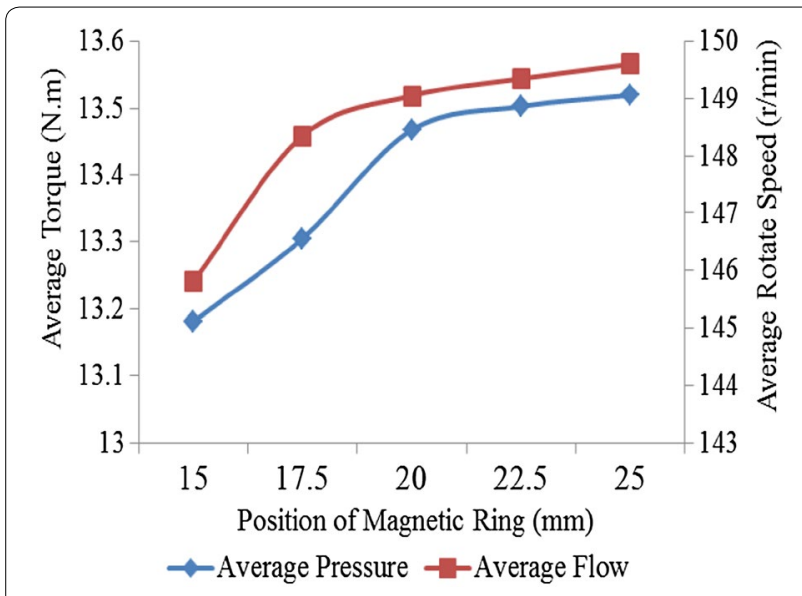

Figure 22 Average torque and rotate speed trend curves

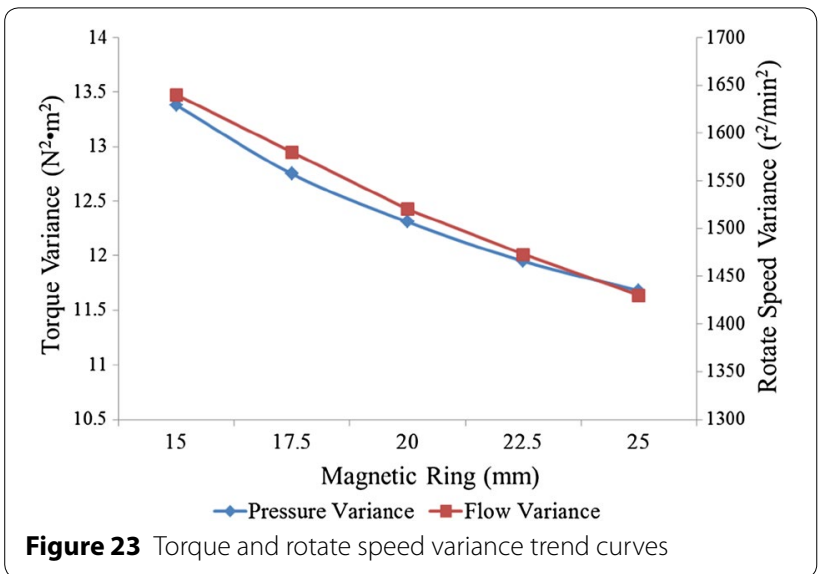

\section{Conclusions}

In this paper, for setting the foundation of the performance optimization of sustainable energy vehicle, a new type of expansion energy used air-powered vehicle is proposed, and the mathematical model and output dynamic characteristics were analyzed by studying influences of the key parameters. Finally we get conclusions as follows:

(1) Simulation and experimental results are consistent with each other which demonstrate the mathematic model to be effective.

(2) For the system of sustainable energy vehicle, input air pressure won't influence the dynamic characteristics and should be set according to the request of the practical loads.

(3) As a key parameter of the structure of the pneumatic-hydraulic transmission, area ratio of the system is considered to be set to 8 approximately which makes system output capacity highest and dynamic characteristics best.

(4) A bigger orifice with a limit will promote the dynamic characteristic property of the power system, but an oversize orifice will cause instability and even make the principle of the orifices throttling invalid. It is considered to be about $20 \mathrm{~mm}$ in the simulation.

(5) Farther position of the rings will increase the quality of output dynamic characteristics, but piston will stop working with too far position of the rings.

This paper provides a basis for optimization of sustainable energy vehicle, especially in the field of compressed air-driven air-powered vehicle with pneumatic-hydraulic transmission.

\section{Authors' contributions}

All authors read and approved the final manuscript.

\section{Author details}

${ }^{1}$ School of Automation Science and Electrical Engineering, Beihang University, Beijing 100191, China. ${ }^{2}$ The State Key Laboratory of Fluid Power \& Mechatronic Systems, Zhejiang University, Hangzhou 310027, China.

\section{Authors' Information}

Xiang-Heng Fu born in 1983, is currently a PhD candidate at School of Automation Science and Electrical Engineering, Beihang University, China. He received his master degree on mechano-electronic from Beihang University, China, in 2013.

Mao-Lin Cai born in 1972, is currently a professor at School of Automation Science and Electrical Engineering, Beihang University, China. His main research direction includes pneumatic and hydraulic fluidics, compressed air energy storage, pneumatic pipe line system.

Yi-Xuan Wang born in 1989, is currently a PhD candidate at School of Automation Science and Electrical Engineering, Beihang University, China. He received his master degree on mechano-electronic from Beihang University, China, in 2015 
Yan Shi born in 1981, is currently an associate professor at School of Automation Science and Electrical Engineering, Beihang University, China. He received his $\mathrm{PhD}$ degree on mechanical engineering from Beihang University, China. His research interests include intelligent mechanical devices and energy-saving technologies of pneumatic system.

\section{Acknowledgements}

Supported by National Natural Science Foundation of China (Grant No. 51375028).

\section{Competing interests}

The authors declare that they have no competing interests.

Ethics approval and consent to participate

Not applicable.

\section{Publisher's Note}

Springer Nature remains neutral with regard to jurisdictional claims in published maps and institutional affiliations.

Received: 27 March 2017 Accepted: 16 January 2018

Published online: 28 February 2018

\section{References}

1. J Li, C F Li, Y X Zhang, et al. Compressed air energy storage system exergy analysis and its combined operation with nuclear power plants. Applied Mechanics and Materials, 2014, 448: 2786-2789.

2. A J Pimm, S D Garvey, M D Jong. Design and testing of energy bags for underwater compressed air energy storage. Energy, 2014, 66(2): 496-508.

3. D Wolf, M Budt. LTA-CAES-A low-temperature approach to adiabatic compressed air energy storage. Applied Energy, 2014, 125(2): 158-164.

4. P Zhao, Y Dai, J Wang. Design and thermodynamic analysis of a hybrid energy storage system based on A-CAES (adiabatic compressed air energy storage) and FESS (flywheel energy storage system) for wind power application. Energy, 2014, 70(3): 674-684

5. X Zhuang, R Huang, C Liang, et al. A coupled thermo-hydro-mechanical model of jointed hard rock for compressed air energy storage. Mathematical Problems in Engineering, 2014, 9(2): 1-11

6. F Creutzig, A Papson, L Schipper, et al. Economic and environmental evaluation of compressed-air cars. Environmental Research Letters, 2009, 4(4): 44011-44019.

7. YT Shen, Y R Hwang. Design and implementation of an air-powered motorcycles. Applied Energy, 2009, 86(7-8): 1105-1110.
8. O Takeuchi, T Fujita, T Kagawa. Characteristics analysis of expanding-type booster. Proceedings of Autumn Symposium on Hydraulics and Pneumatics, 1995: 69-72. (in Japanese)

9. Haipeng Ren, Juntao Fan. Adaptive backstepping slide mode control of pneumatic position servo system. Chinese Journal of Mechanical Engineering, 2016, 29(5): 1003-1009.

10. T Wang, Y Song, L Huang, et al. Parameter tuning method for dither compensation of a pneumatic proportional valve with friction. Chinese Journal of Mechanical Engineering, 2016, 29(3): 607-614.

11. X Yan, M Primot, F Plestan. Comparison of differentiation schemes for the velocity and acceleration estimations of a pneumatic system. IFAC Proceedings Volumes, 2014, 47(3): 49-54.

12. M Taleb, A Levant, F Plestan. Pneumatic actuator control: Solution based on adaptive twisting and experimentation. Control Engineering Practice, 2013, 21(5): 727-736.

13. M L Cai, Y Wang, Y Shi, et al. Output dynamic control of a late model sustainable energy automobile system with nonlinearity. Advances in Mechanical Engineering, 2016, 8(11): 1687814016672784.

14. Y Shi, M L Cai. Working characteristics of two kinds of air-driven boosters. Energy Conversion \& Management, 2011, 52(12): 3399-3407.

15. Y Shi, M Cai, G Wang. Study on air-supplied with different pressure and locally pressure-boosting technology of pneumatic system. Machine Tool \& Hydraulics, 2010, 38(9): 57-59.

16. Y Shi, M Cai. Dimensionless study on output flow characteristics of expansion energy used pneumatic pressure booster. Journal of Dynamic Systems Measurement \& Control, 2013, 135(2): 021007.

17. M L Cai, K Kawashima, T Kagawa. Power assessment of flowing compressed air. Journal of Fluids Engineering, 2006, 128(2): 402-405.

18. Y Shi, Y Wang, $\mathrm{H}$ Liang, et al. Power characteristics of a new kind of air-powered vehicle. International Journal of Energy Research, 2016, 40(8): 1112-1121.

19. Y Shi, Tie-Cheng Wu, Mao-Lin Cai, et al. Energy conversion characteristics of a hydropneumatic transformer in a sustainable-energy vehicle. Applied Energy, 2016, 1(171): 77-85.

20. Y Shi, $T C W u, M L C a i$, et al. Modelling and study on the output flow characteristics of expansion energy used hydropneumatic transformer. Journal of Mechanical Science \& Technology, 2016, 30(3): 1163-1170.

21. Q Yu, Y Shi, M L Cai, et al. Fuzzy logic speed control for the engine of an air-powered vehicle. Advances in Mechanical Engineering, 2016, 8(3): 1-11.

22. Y Shi, Y Wang, M Cai, et al. An aviation oxygen supply system based on a mechanical ventilation model. Chinese Journal of Aeronautics, 2017, https://doi.org/10.1016/j.cja.2017.10.008.

23. W Q Xu, Y Shi, J Niu, et al. Study on air flow dynamic characteristic of mechanical ventilation of a lung simulator. China Science: Technology Science, $2017,60(2): 1-8$

\section{Submit your manuscript to a SpringerOpen ${ }^{\circ}$ journal and benefit from:}

- Convenient online submission

- Rigorous peer review

- Open access: articles freely available online

- High visibility within the field

Retaining the copyright to your article

Submit your next manuscript at springeropen.com 